\title{
Book Department
}

Armstrong, George S. Essentials of Industrial Costing. Pp. 297. Price, \$5.00. New York: D. Appleton \& Co., 1921.

The method of development used by the author of this volume is somewhat different from that which is usually found in books of this nature. Exposition of the fundamentals of cost accounting is most frequently accomplished either by a theoretical discussion of the principles involved, or by an explanation of the entries made upon the books to record the cost data and to transfer such data to the general accounts. In this book the author has developed the subject theoretically and at the same time demonstrated the application of the theory. This is the proper method of exposition. The principles are discussed and suggested forms displayed. It is, however, unfortunate that the author chose to postpone the discussion of the contact between the general books and the cost records until the end of the volume. The reviewer believes that such contact would have been more clearly explained if it had been demonstrated progressively throughout the book. Despite this fact there is more continuity of thought than usual in writings upon this subject.

The introductory chapters relating to the necessity, purpose and function of costing are admirably written and place the reader in a most receptive mood for the technical matter which follows. The author's style of writing is unusual for this type of work; his descriptions are concrete, and his vocabulary such that he is able to avoid the constant use of set phrases which are so much in evidence in contemporary literature of this character.

The explanation of the various cost records is logical and there is a wealth of illustrations and charts which help to visualize the problems set forth. The charts are of more than passing interest in that they have evidently been taken from business experience rather than prepared for purposes of explanation. The tables illustrating "power," which are worked out on a horsepower basis, are particularly noteworthy.
The connection of the cost records with the general books has been brought out by a series of ledger accounts and an excellent chart demonstrating the entries involved. This is a most important portion of the work and proves to be an adequate summary of the fore-going subject matter.

The reviewer does not entirely agree with the author upon the question of the inclusion of interest in cost, or with his broad statement concerning appreciation, but these matters are open questions and from the viewpoint of the author have been satisfactorily handled.

The volume is sufficient as a condensed reference book upon the principles of costing and has special value in that it includes enough technical material to give a thorough explanation without being too complex for those whose knowledge of the subject is limited.

Thomas A. Budd.

Fassett, Charles M. Handbook of $\mathbf{M u}$ nicipal Government. Pp. 160. Price, \$1.50. Assets of the Ideal City. Pp. 160. Price, \$1.50. New York: Thomas Y. Crowell Company, 1922.

These companion volumes by the former Mayor of Spokane, now connected with the University of Kansas as Specialist in Municipal Government, are in no sense a contribution to, but rather a restatement in compact form of the leading facts in the development and structure of city government and an outline of approved principles in municipal functions. Three-fourths of the first volume is taken up with a sketch of existing forms of city government in the United States, the best portions of which are found in the chapters on elections and appointments and the duties of officers. The volume closes with chapters outlining the general problems of administering the city services and local finance.

The Assets of an Ideal City, as its title would indicate, concerns itself with principles rather than with description of existing realities in municipal functions. There are chapters on Streets, Utilities, Health, Corrections, Recreation, Music 